\title{
Activity Types Selection in Kindergarten Outdoor Education
}

${ }^{1}$ Tsai,Yao-Hsu, ${ }^{2} \mathrm{Hou}$, Cheng-I, ${ }^{3}$ Lo, Chih-Yao, ${ }^{4 \star}$ Liu,Hsin-Ying

${ }^{1}$ Dept of Hospitality Management, Chung Hua University, No 707 Sec 2, WuFu Rd, Hsinchu Taiwan

1 happy4golf2007@gmail.com

${ }^{2}$ Department of Leisure Management, Yu Da University of Science and Technology, Hsueh-fu Rd., Tanwen

Village, Chaochiao Township, Miaoli County, 361 Taiwan

${ }^{2}$ cheng@ydu.edu.tw

${ }^{3}$ Department of Information Management, Yu Da University of Science and Technology, Hsueh-fu Rd., Tanwen Village, Chaochiao Township, Miaoli County, 361 Taiwan

3jacklo@ydu.edu.tw

${ }^{4}$ Department of Leisure Management, Yu Da University of Science and Technology, Hsueh-fu Rd., Tanwen Village, Chaochiao Township, Miaoli County, 361 Taiwan

\section{ABSTRACT}

4* hainying0326@hotmail.com

Preschool education develops from focus on physical cultivation in traditional agricultural society to professional education in professional institutions such as kindergartens. In recent years, it emphasizes multiple development and interactive instruction. By field perception, it constructs multi-dimensional and multi-level instruction. Outdoor education is gradually valued and operated. Through personal experience and interactive learning, it explores the meanings of natural environment and culture, learns responsibility and cognition, enhances application and thinking capacity, cultivates the correct concept of environmental protection, social justice and life recognition in order to accomplish the goals of environmental education and diverse development and be different from rigid and limited knowledge and learning of traditional books in schools.

This study focused on selection of activity types in kindergarten outdoor education. Based on literature review, this study designed semi-open-ended questionnaire to collect expert opinions, and used expert questionnaire of Modified Delphi Method for individual interview. According to expert opinions, the important factors were identified. Finally, AHP questionnaire was designed.

This study discussed the concerns and preferences of kindergartens in Miaoli County regarding outdoor education in research process. The results revealed the expectation of residents in Miaoli County, educational experts and scholars and governmental personnel toward talent cultivation.

\section{Indexing terms/Keywords}

preschool education, outdoor education, semi-open-ended questionnaire, Modified Delphi Method

\section{Council for Innovative Research}

\author{
Peer Review Research Publishing System
}

\section{Journal: INTERNATIONAL JOURNAL OF COMPUTERS \& TECHNOLOGY}

Vol.14, No.6

www.ijctonline.com, editorijctonline@gmail.com 


\section{INTRODUCTION}

Preschool education in Taiwan changes from original single teaching material instruction to multi-instructional model. Hence, by different instructional models, children learn and grow with various effects. Research of Lu [1] demonstrated that preschool education in Taiwan is based on kindergartens and it changes from quantitative to qualitative growth. With the influence of development on preschool education research and innovative instruction, Taiwan government is devoted to development of different instructional models. By experiment, it validates the effectiveness, such as discovery learning model, behavioral instruction model, unit design instructional model, experimental model of science education, activity instruction model, etc.

In recent years, the government is devoted to implementation of outdoor education to allow children to learn by direct experience. According to research of Hsieh [2], in actual operation of outdoor education, children experience and feel in reality. By personal experience and interaction, it recognizes various kinds of culture in real life, enhances chlidren's learning efficiency and development and practices instruction by diverse resources in outdoor environment to accomplish the goals of school curriculum.

Based on research of Rivkin [3], students should have direct experience and perception in natural environment. By personal experience, they develop personal cognition and affection. Through different types of sensory stimulus, students have total experience and cognition and learn in relaxing and free environment.

Research of Andrew \& Willingham [4] found that in this century, new concept of environmental education is thematic learning model. Children are cultivated with responsible attitude and self-consciousness in reality and develop critical and thinking competence. They develop social values by approaching environmental issues and live with interaction and cooperation.

Topic of this study is to discover outdoor education selection and evaluation factors of kindergartens in Miaoli County regarding preschool education. The research methods are literature review, Modified Delphi Method to find the key factors.

\section{LITERATURE REVIEW}

By related literature and research tool review, this study analyzed the common factors of activity selection in outdoor education and research methods.

\section{Common Factors of Activity Selection in Outdoor Education 2.1}

The researcher reorganizes the previous data as follows: (see Table 1)

Table 1.Select features outdoor teaching considerations

\begin{tabular}{|c|c|c|}
\hline \multicolumn{3}{|r|}{ Select features outdoor teaching considerations } \\
\hline Source & Era & Content \\
\hline $\begin{array}{l}\text { Wang Wang } \\
\text { Jing Ru【5】 }\end{array}$ & (1991) & 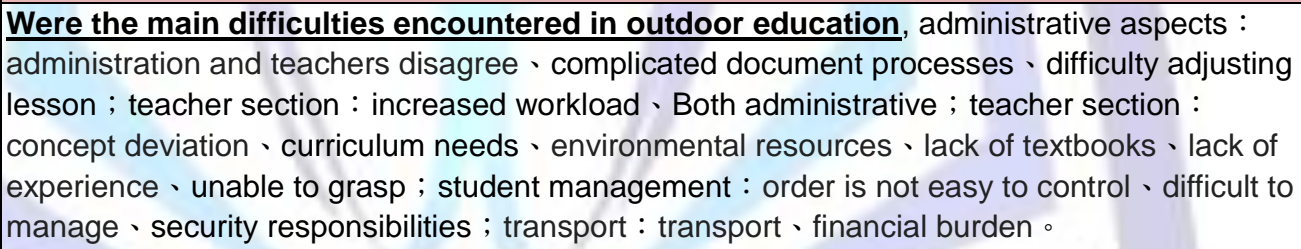 \\
\hline $\begin{array}{l}\text { Shiu Rung } \\
\text { Chung 【6】 }\end{array}$ & $(1996)$ & $\begin{array}{l}\text { Local school teachers in teaching outdoor education Factors that influence: teaching } \\
\text { time } \cdot \text { economic conditions } \cdot \text { security concerns }- \text { schools recognized } \cdot \text { teacher wishes }\end{array}$ \\
\hline Simmons【7】 & $(1998)$ & $\begin{array}{l}\text { Primary teachers affect outdoor education factor : student safety concerns - courses } \\
\text { urgent } \text { no professional knowledge and ability } 、 \text { no outdoor teaching resources } \\
\text { administrative units are not supported 、low teacher wishes 、 information gaps 。 }\end{array}$ \\
\hline $\begin{array}{l}\text { Shie Hung Ru } \\
\text { 【2】 }\end{array}$ & $(2000)$ & 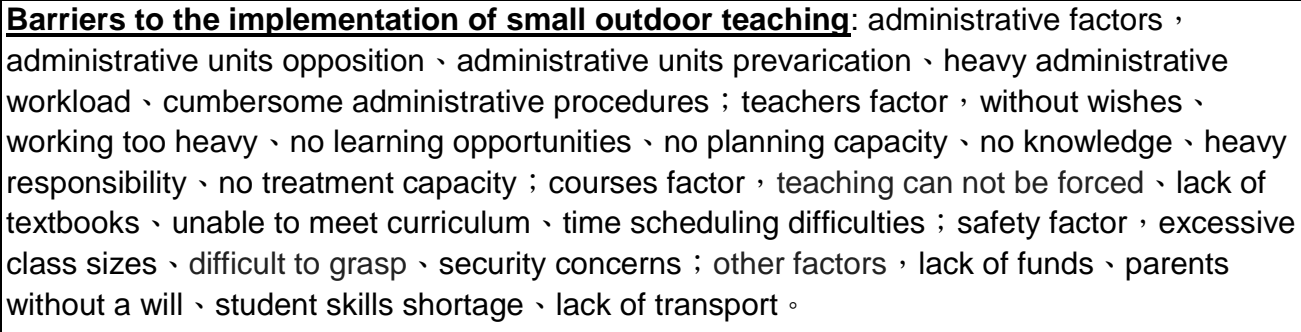 \\
\hline $\begin{array}{c}\text { Yu Tzung Han } \\
\text { 【8】 }\end{array}$ & $(2000)$ & $\begin{array}{l}\text { Teachers use the outdoor teaching resource impact factor: factors some students, class } \\
\text { size - class Order - student wishes - security considerations ; teacher factors section, } \\
\text { workload, wishes, attitudes, knowledge ; school factors section, policy support, funding ; } \\
\text { courses factors section, progress, problems, information ; teaching resources section, lack of } \\
\text { resources, traffic considerations. }\end{array}$ \\
\hline
\end{tabular}




\begin{tabular}{|c|c|c|}
\hline $\begin{array}{l}\text { Lin Jr Huei } \\
\text { 【9】 }\end{array}$ & (2000) & $\begin{array}{l}\text { Select principle outdoor teaching learning activities: available exercises - has a number of } \\
\text { goals - elaborate structural materials - diverse activities } 、 \text { students' abilities and needs - with } \\
\text { the school curriculum 、emphasis on community collaboration to develop independence }\end{array}$ \\
\hline $\begin{array}{l}\text { Shiung Shiang } \\
\text { Bing Ping } \\
\text { 【10】 }\end{array}$ & ( 2002 ) & $\begin{array}{l}\text { Factors affecting the implementation of outdoor education: class size } \cdot \text { the safety of } \\
\text { students, teachers and professional wishes, local resources, materials, administrative staff } \\
\text { support, curriculum, education policy unit } \text {. }\end{array}$ \\
\hline $\begin{array}{l}\text { Jeng Shuen } \\
\text { Wan【11】 }\end{array}$ & (2002) & $\begin{array}{l}\text { Difficulty factor of outdoor education teacher: of students and management control for } \\
\text { security reasons, in order to increase the burden on teachers and the lack of professional and } \\
\text { administrative aspects of cooperation, environmental resources, knowledge and resources for } \\
\text { activities designed to handle the lack of time, lack of funding and lack of transport }\end{array}$ \\
\hline $\begin{array}{l}\text { Huang Su } \\
\text { Feng【12】 }\end{array}$ & (2002) & $\begin{array}{l}\text { The value of outdoor education: the students, increase learning fun, cultivate scientific } \\
\text { knowledge and ability to enhance the knowledge, conservation optimistic and positive attitude, } \\
\text { build interpersonal, prompting physical and mental integrity; teachers, training teachers and } \\
\text { emotions, enhancing the teaching profession, improve teaching skills; curriculum, teaching } \\
\text { diverse of providing practical experience, adapt urban-rural gap }\end{array}$ \\
\hline $\begin{array}{c}\text { Tsai Shu Huei } \\
\text { 【13】 }\end{array}$ & (2004) & $\begin{array}{l}\text { Primary teachers to influence ecotourism outdoor teaching wishes: eco-part tour, site } \\
\text { safety, distance, ecology content itinerary; teaching part, professional tour, part of the school } \\
\text { curriculum with the degree, teaching depth, with the school environment; the student section, } \\
\text { the number of students in grades required costs; teacher part, teacher familiarity }\end{array}$ \\
\hline $\begin{array}{c}\text { Tsai Shu Huei } \\
\text { 【13】 }\end{array}$ & (2004) & $\begin{array}{l}\text { Primary school teachers affected farm outdoor teaching wishes: teacher older part, } \\
\text { students need UGC seniority, teaching expectations; think school teachers than students Farm } \\
\text { in outdoor teaching Reason: No learning fun, the students are not interested, no places, } \\
\text { teachers without teaching experience, difficult to master student status, administration and } \\
\text { teachers are not supported, the application process complicated, difficult to handle site } \\
\text { coordination, lack of funding, student safety is difficult to control, with a low degree courses, } \\
\text { lack of transport. }\end{array}$ \\
\hline $\begin{array}{c}\text { Shiu Jr } \\
\text { Shuang【14】 }\end{array}$ & (2005) & $\begin{array}{l}\text { The purpose of outdoor teaching: cultured natural affection, enhance relationships, rich } \\
\text { curriculum, implement humane care, increase skills, raise interest and enhance feelings of } \\
\text { teachers and students. }\end{array}$ \\
\hline $\begin{array}{c}\text { Shiu Jr } \\
\text { Shuang 【14】 }\end{array}$ & (2005) & $\begin{array}{l}\text { Educational value of outdoor education: cognitive value, affective value, the value of the } \\
\text { skills of students; the value of some teachers, students and teachers can promote feelings, } \\
\text { enhance professional competence. }\end{array}$ \\
\hline
\end{tabular}

\section{Delphi Method 2.2}

According to research of Linstone \& Turoff [15], when predicting unknown and unexpected cases, RAND Corporation of the U.S. were uncertain due to lack of information. It could not quantify data by sufficient figures and could not have related judgment and prediction. In order to solve the problem, in 1950, it designed Delphi Method. First, it invited the discussion of several experts. By collective opinions and interaction, it reorganized the views, analyzed and inferred the cases. All experts should freely participate in the discussion and thinking. Their views were equally valued and respected. After collecting all opinions, it developed expert consensus, generalized the most important and possible analytical result, and verified its fitness.

\section{Modified Delphi Method 2.3}

According to of Murry \& Hammons [16], the Delphi Method is to first develop an open-ended questionnaire for expert interview. However, the questionnaire must be based on continuous inquiry of opinions, discussion and generalization, thus it is time consuming and may present conflict of opinions. The progress is difficult to control, and consensus may not be reached. The Modified Delphi Method is not based on open-ended questionnaire, and it collects and generalizes data based on literature review. Expert opinions are used to develop a structural questionnaire. The process is rapid, efficient, and can avoid the conflict.

\section{RESEARCH METHOD}

This study aims to analyze selection of activity in outdoor education in childhood instruction of Miaoli County, and discuss the factors of kindergartens when selecting or planning outdoor instruction. Using questionnaire survey and research tools, this study identified important selection dimensions and factors as the reference for related policy construction, implementation, activity planning and activity or research of related personnel. The findings can help to implement children's holistic education in Miaoli County. 


\section{Research Process 3.1}

The research process is as follows: use literature review to identify the dimensions and factors concerned by experts and scholars when selecting activity of outdoor education; semi-open-ended questionnaire is developed to collect the experts' opinions and develop experts' consensus by Modified Delphi Method; reorganize the expert opinions and calculate consistency by AHP to find relative weights (see Figure 1)

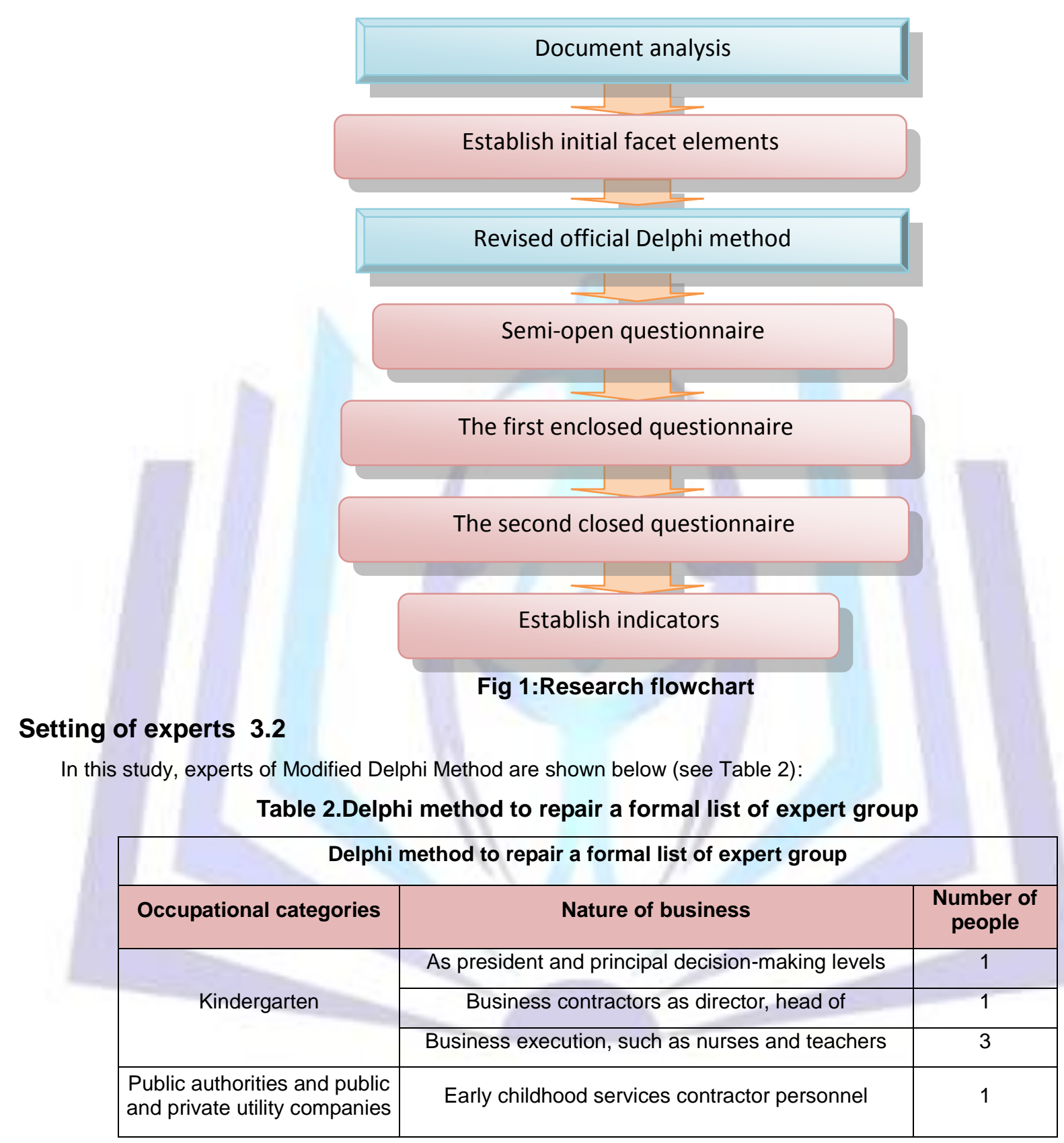

AHP expert setting should be based on the condition of Modified Delphi Method to conduct questionnaire survey in related institutions in Miaoli County.

\section{Questionnaire survey 3.3}

This study adopted Modified Delphi Method questionnaire and AHP expert questionnaire.

1. Modified Delphi Method questionnaire

1) Semi-open-ended questionnaire

Based on literature review, a semi-open-ended questionnaire was designed to collect experts' opinions, which were used to develops 6 dimensions and 37 factors (see Figure 2). 


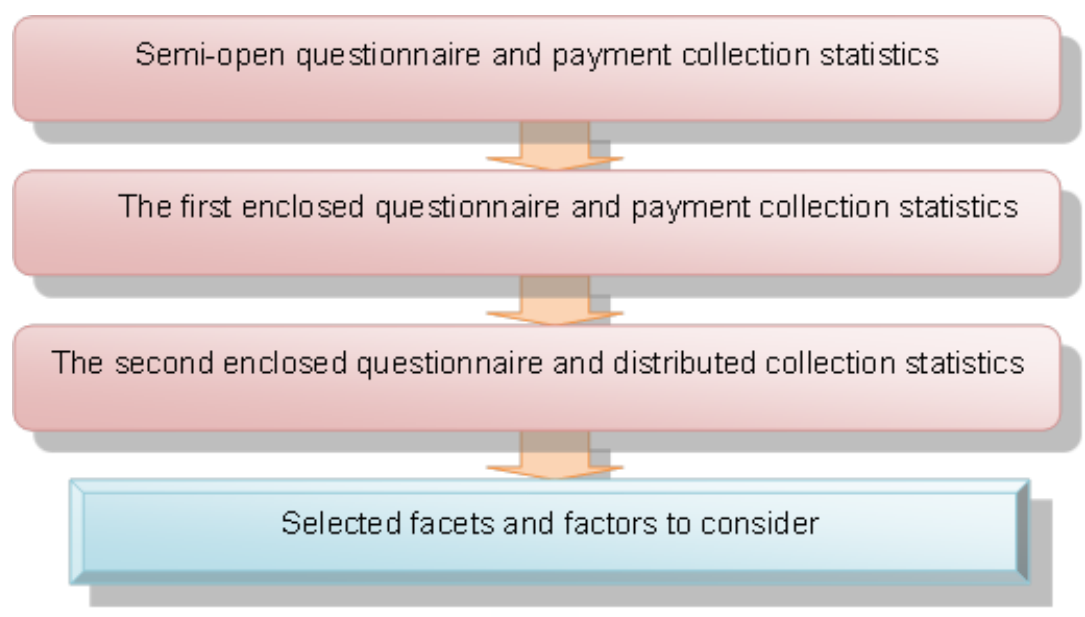

Fig 2:Using the Delphi method of repair formal process

2) The first-round close-ended questionnaire

In this questionnaire, the selection condition of items was determined to be: average mean to be over 3 , and CV to be below 0.5 . Based on the results of the first-round close-ended questionnaire survey, 5 dimensions and 25 factors were obtained.

3) The second-round close-ended questionnaire

The selection condition was: average mean to be over 4 , and $C V$ to be below 0.3 . Based on the results, there were 4 dimensions and 16 factors.

2. AHP expert questionnaire

1) Hierarchical framework

According to dimensions and factors analyzed by Modified Delphi Method, the hierarchical framework was developed.

2) Questionnaire survey

This study first obtained dimensions and factors of Modified Delphi Method and designed AHP expert questionnaire. It conducted individual interview on 25 experts and obtains their opinions. The researcher interviewed the qualified experts in institutions, schools, groups and departments related to preschool education in Miaoli County and invited them to fill in questionnaires.

\section{RESULTS AND ANALYSIS}

By literature review, this study analyzed the weights by Modified Delphi Method.

1. Modified Delphi Method

In the second-round close-ended questionnaire, expert opinions were collected, and this study identified 4 dimensions and 16 factors (see Table 7).

Table 7:Final confirmation indicator

\begin{tabular}{|c|c|c|c|}
\hline \multicolumn{4}{|c|}{ Final confirmation indicator } \\
\hline Facets & Factors to consider & Facets & Factors to consider \\
\hline \multirow{4}{*}{$\begin{array}{c}\text { Students } \\
\text { Facets }\end{array}$} & 1. Student safety concerns & \multirow{4}{*}{$\begin{array}{l}\text { Teachers } \\
\text { facets }\end{array}$} & 1. Increased workload \\
\hline & 2. Number of students in grades & & 2. Teachers' lack of experience \\
\hline & 3. Student skills shortage & & 3. Teacher wishes \\
\hline & 4. Students are not interested in & & 4. Train teachers and emotion \\
\hline \multirow{4}{*}{$\begin{array}{l}\text { Courses } \\
\text { Facets }\end{array}$} & 1. Professionals Tour & \multirow{4}{*}{$\begin{array}{c}\text { School } \\
\text { administrative } \\
\text { facets }\end{array}$} & 1. Schools recognized \\
\hline & 2. Course schedule & & 2. Low administrative unit with the degree of \\
\hline & 3. Increase knowledge and skills & & 3. Difficulty adjusting lesson \\
\hline & 4. Enhance relationships & & 4. Complicated document processes \\
\hline
\end{tabular}




\section{CONCLUSION}

The experts invited in this study were those from fields of kindergarten education, business operation, policy making, publication, research, instruction or other specialty in preschool education. The subjects were mostly based in Miaoli County. Their opinions and local knowledge were collected to analyze the concerns on preschool activity selection of outdoor education in Miaoli County, in order to select the appropriate instructional model.

This study conducted literature review, and used the Modified Delphi Method to create semi-open-ended questionnaire and close-ended questionnaire. Based on experts consensus, there were 4 dimensions and 16 factors: student dimension includes students' security, students' grades, students' lack of skills and students' lack of interest; courses include guide of experts, progress of course, increase of knowledge and skills and enhancement of interpersonal relationship; teacher dimension includes increase of work loading, teachers' lack of experience, teachers' intention and development of relationship between teachers and students; school administration includes school identification, lack of cooperation of administration units, complicated procedure of official documents, difficulty of course switch.

For educators, according to factors with high degree of importance, this study proposes the following suggestions:

1) Students' security

Among factors of outdoor education, teachers treat students' security as the priority. In modern society, people pay more attention to personal rights and parents focus on children' learning environment and safety. When they have questions or dissatisfaction, there will be lawsuits. Hence, teachers' situations and instruction are difficult. Therefore, among factors of outdoor education, children's security should be the priority.

2) Experts' guide

Modern parents are careful about children's learning development and teachers pay attention to instructional quality and effectiveness. However, traditional educators focus on formal curriculum and they lack multiple trainings of outdoor education. Therefore, in outdoor education, teachers mostly expect the assistance from experts' guide and lecture in the instruction. Children will obtain richer and more complete educational resources. Besides, teachers can enhance professional knowledge and skills in learning.

\section{REFERENCES}

[1] Lu Su Bi.1988. For almost four decades of teaching materials and teaching methods of early childhood education. Bulletin of educational materials,13,97-121.

[2] Shie Hung Ru.2000. Research Status of small outdoor education teacher and Obstacles, National Institute of Curriculum and Instruction Taipei University of Education, hesis, Taipei.

[3] Rivkin,M.S..1997. The schoolyard habitat movement: What it is and why childrenneed it. Early childhood education Journal, 25(1),61-66.

[4] Andrew, J. R., \& Willingham, D..2009. 21st century skills: The challenges ahead.Educational Leadership, 67(1), 16-21.

[5] Wang Wang Jing Ru.1991.Kaohsiung-Pingtung area survey small outdoor difficulty analyzing the status of teaching, Primary Education Research,3,363-396.

[6] Shiu Rung Chung.1996. Outdoor design small local geography teaching and analysis, Institute of Geography, National Taiwan University, Thesis, Taipei.

[7] Simmmons, D. .1998.Using Natural Settings for Environmental Education: Perceived Benefits and Barriers. The Journal of Environmental Education, 29(3), 23-31.

[8] Yu Tzung Han.2000.Investigation of outdoor environmental education teaching resources Hualien County Primary Teachers use, National Institute of Science Education small country Hualien Teachers College, Thesis, Hualien County.

[9] Lin Jr Huei.2000. Science teachers serving small country the status of implementation of the Taichung area outdoor teaching natural science research on campus, Taichung Teachers College Natural Sciences Department of Education, Thesis, Taichung.

[10] Shiung Shiang Bing Ping.2002.Local outdoor survey research and teaching activities of the implementation of Pingtung County elementary school teachers, National Institute of Education, National Pingtung Teachers College, Thesis, Pingtung。

[11] Jeng Shuen Wan.2002. Application Taoyuan County Shimenshan Plant Resources and teaching activities in the local environment outdoors, National Normal University, Department of Biology, Master of job training courses in Taiwan, Thesis, Taipei.

[12] Huang Su Feng.2002.Clear of fifth grade to study Banqun outdoor teaching mode, National Institute of Curriculum and Instruction Taipei Teachers College,Thesis, Taipei.

[13] Tsai Shu Huei.2004. Study ecotourism outdoor teaching elementary school teachers in Taipei willingness of ecotourism awareness and, Hualien Teachers College, National Institute of Environmental Ecology and Education,Thesis, Hualien County. 


\section{ISSN 2277-3061}

[14] Shiu Jr Shuang.2005.Outdoor Research Teaching Elementary School implemented Tainan, National Taichung University of Education National Education Institute,Thesis, Taichung.

[15] Linstone, H. A., \& Turoff, M. .1975.The Delphi Study: Technique and Applications.Landon, England: Addison-Wesley Publishing Co.

[16] Murry J.W., and J.O. Hammons.1995. "Delphi: A versatile methodology for conducting qualitative research," The Review of Higher Education, vol. 18, no. 4, p. 423-436.

[17] Saaty, T. L..1980.The Analytic Hierarchy Process, N.Y.: McGraw - Hill.. 